\title{
Thermal Stability of Some Anti-Inflammatory Pharmaceutical Drugs and Determination Of Purity Using (DSC)
}

\author{
Anwar A Wassel* \\ National Organization for Drug Control \& Research, Egypt \\ Received: March 19, 2017; Published: April 10, 2018 \\ *Corresponding author: Anwar A Wassel, National Organization for Drug Control \& Research, Cairo, Egypt, Email: aawassel@iau.edu.sa
}

\begin{abstract}
The thermal behavior of some anti-inflammatory drugs: diflunisal, tenoxicam and celecoxib are studied extensively by thermo gravimetric and differential thermal analyses (TGA/DTA) techniques. The thermo gravimetric data allowed determination of the kinetic and thermodynamic parameters: activation energy (Ea), frequency factor (Z) activation entropy (AS\#) and reaction order (n) which calculated from TG-curves at different heating rates using different kinetic models: The relative thermal stabilities of the anti-inflammatory drugs have been evaluated on the basis of the kinetic and thermodynamic parameters. Also, the purities of these drugs are determined by differential scanning calorimetric (DSC) technique and compared with specialized pharmacopoeia methods. Analysis of the DSC data indicated that the degrees of purity of diflunisal, tenoxicam and celecoxib were similar to those found by pharmacopoeia methods (BP and USP). The simplicity, speed and low operational costs of thermal analysis justify its application in quality control of pharmaceutical drugs.
\end{abstract}

Keywords: Thermal Analysis; TGA and DTA; Differential Scanning Calorimetric (DSC); Anti-Inflammatory Drugs

\section{Introduction}

Several studies have been carried out on the solid state and the applicability of thermal analysis to investigate analgesic and antirhumatic agents [1-5]. The interactive nature of diflunisal, tenoxicam and celecoxib used in tablet formulation is the subject of the present investigation. Diflunisal, $\left(22^{\prime} 4^{\prime}\right)$ difluoro-4-hydroxy-(1,1)-biphenyl-3-carboxylic acid. Is a derivative of salicylic acid similar to aspirin. Tenoxicom, 4 - hydroxyl - 2 - methyl-N-2pyridy 2H-thieno [2,3-c]-l,2-thiazine-3-carboxamide 1,1-dioxide. , is a non steroidal ant rheumatic drug belongs to oxicam group. Celecoxib,4-[5-(4-methylphenyl)-3-trifluoromethyl]-1-hyrazbenzenesulfonami, is non steroidal anti inflammatory drug belongs to cyclogenase inhibitor group. Ford et al [6]. Pointed out the use of thermal analysis in the characterization of the pharmaceutical drugs and the use of thermal analysis in the development of solid dosage forms. Thermo gravimetric (TG/DTG) is an analytical, quantitative and comparative method, capable of producing fast and reproducible results.

In this technique the change in a sample mass is determined as a function of temperature. It can be used in the quality control of drugs, with a view to improvement of the final product and for the determination of drug quality via the technological parameters [7].
It is an effective method of studying thermal stability and kinetic parameters of the decomposition of drugs and medicine [8-10]. The differential scanning calorimetric (DSC), also, can be used in the pharmaceutical industry as analytical tools of great importance for the identification and purity testing of active drugs, yielding results rapidly and efficiently [11-12]. DSC has been applied for the quality control of raw materials used in pharmaceutical product [13]. The present work reports studies of the thermal behavior of some antiinflammatory drugs, in comparison with the methods employed for identification and purity testing in the pharmaceutical industry [14-15]. In relation to the application of thermal techniques in the quality control of medications.

\section{Experimental}

The dynamic thermo gravimetric curves of diflunisal, tenoxicam and celecoxib were recorded on Shimadzu thermo balance, model DTG-60H, under a nitrogen atmosphere with constant flow of 50 $\mathrm{mL}$ min-1, at heating rates of 5,7.5,10, 20 and $30{ }^{\circ} \mathrm{C}$ min- 1 , up to a temperature $600{ }^{\circ} \mathrm{C}$, sample with a mass of around $10 \mathrm{mg}$ were packed in alumina cell. The calorimetric curves of anti-inflammatory drugs were obtained with Shimadzu differential scanning calorimeter, model DSC-50. Under an atmosphere of nitrogen, with 
a constant flow of $30 \mathrm{~mL} \mathrm{~min}-1$ and a heating rate of $10{ }^{\circ} \mathrm{C}$ min- 1 , up to a temperature of $500{ }^{\circ} \mathrm{C}$, Samples with a mass of $2 \mathrm{mg}$ were packed in an alumina cell. The purity determination was performed using heating rate of $20 \mathrm{C} \mathrm{min}-1$, up to a temperature range from 25 to $250 \mathrm{C}$ in nitrogen d-masphere with flow rate $30 \mathrm{ml} \mathrm{min}-1$. The To, Ts and $\Delta$ Hfusion were calculated. The kinetic and thermodynamic parameters of decomposition, the activation energy (Ea), reaction order (n), frequency factor (Z), the activation entropy (AS\#), were obtained from thermo gravimetric curves (TG), using $(\alpha)$ values of 0.1-0.4 for diflunisal and tenoxicam and of 0.2-0.8 for celecoxib. The mathematical models of Kissinger [14]. Flynn-Wall-Ozawa [16-17]. Coats and Redfern [18,19]. Madhusudanan [20], and HorowitzMetzger [21], applicability of these methods to the pharmaceutical drugs in the conversion range studied.

\section{Results and Discussion}

The thermo gravimetric curves (Figure 1). Were analyzed by the tangent method, calculated from the curve of mass loss versus temperature. Calculations on the range of temperatures and the respective mass losses were performed with the aid of shimadzu software and excel programs. The TG-curves of Diflunisal revealed four thermal decomposition stages. The weight losses were calculated for the different steps and compared with those theoretically calculated for the suggested decomposition. TGcurves, Figure la, shows that the weight loss percentage $7.5 \%$ (calc.7.2\%) at temperature range $100-200{ }^{\circ} \mathrm{C}$, this can be attributed to the removal of one the combined water. In the second step of decomposition within $200-220{ }^{\circ} \mathrm{C}$ temperature range is matched with the calculated value $(11.2 \%)$ corresponding to the removal of carbon monoxide molecule. The third step of decomposition is matched with the calculated value (calc.15.998\%) represent the removal of two molecules of HF within temperature range 220-240 ${ }^{\circ} \mathrm{C}$. The fourth step of degradation corresponding to loss of 66.63 $\%$ (calc. $66.4 \%$ ) represent the removal of remaining organic parts of diflunisal within temperature range $240-600{ }^{\circ} \mathrm{C}$, while no the weight remaining is not present.

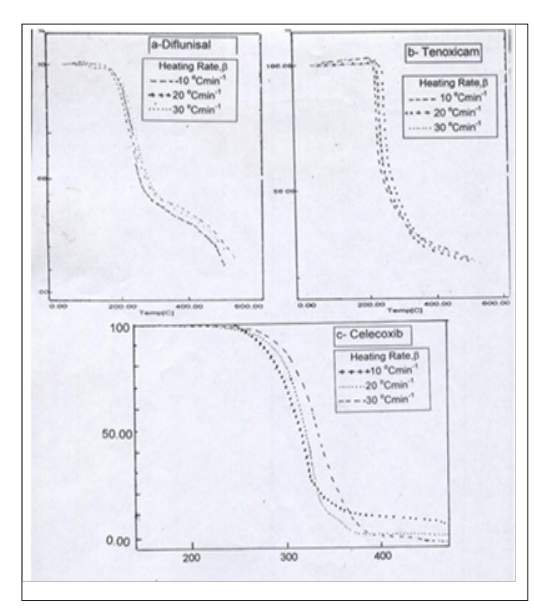

Figure 1: TG-curves of the thermal decomposition at different heating rates of a -Diflunisal, b- Tenoxicam and c-celecoxib drugs.

The DTA show that an endothermic peak at 218 0C due to melting and another endothermic peak at 280 OC due decomposition of the compound. Other exothothermic peaks at 400 OC due to complete decomposition of the compound. From TG-curves of Tenoxicam, (Figure 2). The weight losses are 46.479 (46.56), 20.36 (20.46), 8.5 (8.3) and $15.22 \%$ (15.42\% calc.), respectively. The first one observed in the temperature range 120 $250{ }^{\circ} \mathrm{C}$ is attributed to removal of SO2, N2 and $2 \mathrm{C} 2 \mathrm{H} 2$, whereas the second step corresponds to the removal of C3H3NO (within the temperature range $250-330{ }^{\circ} \mathrm{C}$ ). The third step corresponding to the removal of $\mathrm{CO}$ molecule within temperature ranges $330-350{ }^{\circ} \mathrm{C}$. The last one corresponds to the removal of remaining of organic parts ( $\mathrm{C} 4 \mathrm{H} 4)$ two molecules of acetylene within temperature range $350-600{ }^{\circ} \mathrm{C}$. The remaining weight $\%$ of 9.67 is matching with the calculated value of $9.48 \%$ pointing to the decomposition of this drug into sulphur.

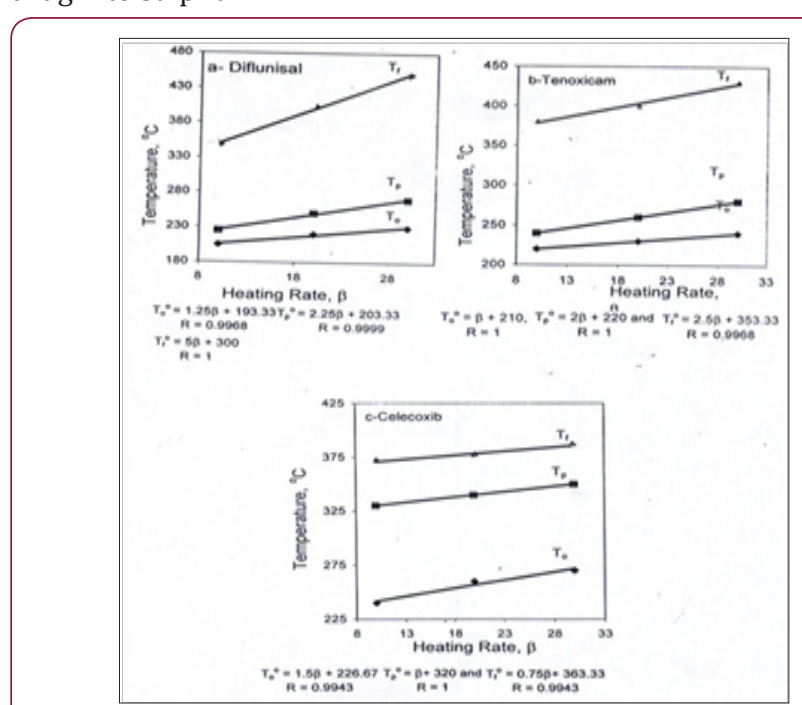

Figure 2: Plots of the thermal decomposition temperatures versus heating rates.

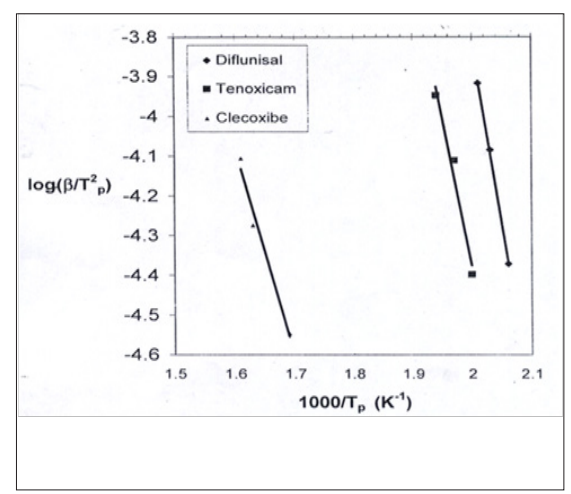

Figure 3: plots of the thermal decomposition temperatures versus heating rates according to Kissinger method.

Figure 3 represent the weight losses of celecoxib were $21.10,43.66,18.20$ and $16.90 \%$, the first step of decomposition representing the removal of $\mathrm{SO} 2$ and $\mathrm{NH} 3$ molecule in temperature range $100-300{ }^{\circ} \mathrm{C}$ is in a good agreement with the theoretical value $20.98 \%$. The second step within the temperature range 300-360 ${ }^{\circ} \mathrm{C}$ represents loss of biphenyl nucleus (C13H8) calculated value $43.38 \%$. The third step of decomposition attributed to loss of CHF3 within temperature range $360-400{ }^{\circ} \mathrm{C}$ is matching to theoretically 
value $18.09 \%$. The last one represents the removal of the organic residue of celecoxib molecule within temperature range 400-600 ${ }^{\circ} \mathrm{C}$ is in agreement with the calculated value of $16.78 \%$. Figure 4 shows that the heating rates affect on the temperatures at the maximum weight-loss rate $\left(\mathrm{T}_{\mathrm{p}}\right)$, at the start $\left(\mathrm{T}_{0}\right)$ and at the end $\left(\mathrm{T}_{\mathrm{f}}\right)$ of the weight-loss stages. It was found that the values of $\mathrm{T}_{0}, \mathrm{~T}_{\mathrm{p}}$ and $T_{f}$ increase with increasing of heating rate $(\beta)$. The equilibrium degradation temperatures are gained by extrapolation of $\mathrm{T}_{0}, \mathrm{~T}_{\mathrm{p}}$ and $\mathrm{T}_{\mathrm{f}}$ to $\beta=0 ; \mathrm{T}_{0}=193.33, \mathrm{~T}_{\mathrm{p}}=203$ and $\mathrm{T}_{\mathrm{f}}=300{ }^{\circ} \mathrm{C}$ for diflunisal, $\mathrm{T}_{0}=$ $210, \mathrm{~T}_{\mathrm{p}}=220$ and $\mathrm{T}_{\mathrm{f}}=353.33^{\circ} \mathrm{C}$ for tenoxicam and $\mathrm{T}_{0}=226.67, \mathrm{~T}_{\mathrm{p}}=$ 320 and $\mathrm{T}_{\mathrm{f}}=363.33^{\circ} \mathrm{C}$ for celecoxib.

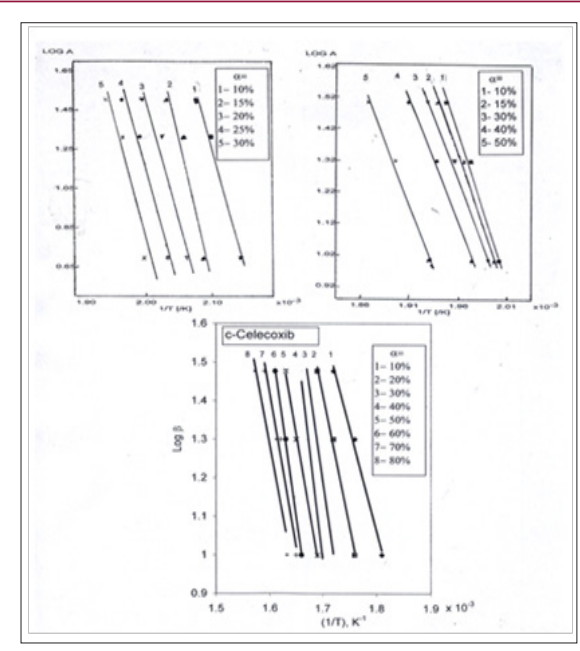

Figure 4: plots of the thermal decomposition temperatures versus heating rates according flvnn-wall-ozava method.

of 220.7 and 151.4 and $101.22 \mathrm{~kJ} / \mathrm{mol}$ were found for diflunisal, tenoxicam and celecoxib, respectively. Also these values show that the activation energy is very close to the value obtained using Kissinger method. The kinetic data were calculated for the other two mathematical models (Coats \& Redfern and Madhusudanan) in the different conversions ranges $(\alpha)$ in order to choose the best linear correlation coefficients $(r)$. The results led to the following values; diflunisal $(\alpha=10-30 \%)$ : CR $(r=1.00)$, MD $(r=1.00)$; tenoxicam $(\alpha$
Using Kissinger method, the activation energy can be calculated from a plot of $\log \beta / \mathrm{T} 2$ versus (1000/T) (Figure 5). The obtained activation energies are 174.94, 145.796 and $101.220 \mathrm{~kJ} / \mathrm{mol}$ for diflunisal, tenoxicam and celecoxib, respectively. The activation energy can also be determined using the method of Flynn-Wall Ozawa, from linear fitting of $\ln \beta$ versus $(1000 / \mathrm{T})$ at different conversion values. Owing to the fact that the equation of FlynnWall-Ozawa, was derived using the Doyle approximation only conversion values in the low range as well as a high range can be used. For this study, we have used the conversion values $9,14,19$, 24 and $30 \%$ for diflunisal and 8,12, 27, 37 and $45 \%$ for tenoxicam and 20, 40, 60 and 80 for celecoxib. Figure 4, shows that the fitting straight lines are a nearly parallel, thus indicating applicability of this method to the pharmaceutical drugs (diflunisal, tenoxicam and celecoxib) in the conversion range studied. This fact suggests that a single reaction mechanism is operative [24,25].

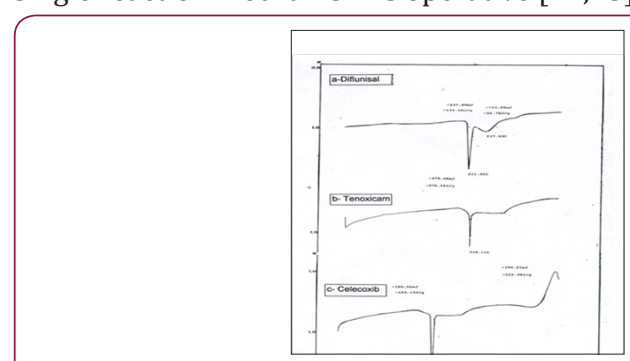

Figure 5: The differential of scanning calorimetric (DSC) analysis of a- Diflunisal, b-Tenixicam and c- celecoxib.

Activation energy values corresponding to the different conversions are determined. From these values a mean value -8-50\%); CR ( $\mathrm{r}-1.00), \mathrm{MD}(\mathrm{r}=1.00)$; celecoxib ( $\alpha-10-80 \%)$; CR $(\mathrm{r}=$ $1.00), M D(r=1.00)$. The kinetic parameters; the activation energy (Ea) and frequency factor (Z) demonstrated significant differences between the three anti-inflammatory drugs. The activation energies according to Kissinger, Flynn-Wall-Ozawa are in a good agreement with those obtained using the Coats-Redfern and Madhusudanan methods Table 1.

Table 1: The kinetic and thermodynamic parameters of anti-inflammatory drugs.

\begin{tabular}{|c|c|c|c|c|c|c|}
\hline \multirow[b]{2}{*}{ Method } & \multirow[b]{2}{*}{ Drug } & \multicolumn{5}{|c|}{ Parameter } \\
\hline & & $\begin{array}{l}\text { Order reaction } \\
\text { (n) }\end{array}$ & $\begin{array}{l}\text { Activation energy } \\
\text { (Ea) kJ mol-1 }\end{array}$ & $\begin{array}{c}\text { Frequency factor } \\
\text { (Z) s-1 }\end{array}$ & $\begin{array}{c}\text { Activation } \\
\text { Entropy- }(\Delta s \#)\end{array}$ & $\begin{array}{l}\text { Correlation } \\
\text { coefficient }(r)\end{array}$ \\
\hline \multirow{3}{*}{ Kissinger } & Dflunisal & 1.0 & 174.94 & 0.195 & 114.29 & 0.9994 \\
\hline & Tenoxicam & 1.0 & 145.78 & 0.161 & 115.07 & 0.9860 \\
\hline & Celecoxib & 1.0 & 101.22 & 0.097 & 117.399 & 0.9892 \\
\hline \multirow{3}{*}{ Ozawa } & Dflunisal & 1.3 & 220.70 & 0.248 & 113.44 & 0.9961 \\
\hline & Tenoxicam & 1.3 & 151.41 & 0.181 & 114.94 & 0.9980 \\
\hline & Celecoxib & 1.3 & 111.27 & 0.101 & 118.359 & 0.9994 \\
\hline \multirow{3}{*}{ Coats \& Redfern } & Dflunisal & 1.0 & 190.80 & 0.220 & 113.87 & 1.0 \\
\hline & Tenoxicam & 1.0 & 147.63 & 0.164 & 114.38 & 1.0 \\
\hline & Celecoxib & 1.0 & 85.89 & 0.086 & 118.41 & 1.0 \\
\hline \multirow{3}{*}{ Madhusudanan } & Dflunisal & 1.0 & 195.71 & 0.211 & 111.31 & 1.0 \\
\hline & Tenoxicam & 1.0 & 140.31 & 0.152 & 116.51 & 1.0 \\
\hline & Celecoxib & 1.0 & 90.57 & 0.095 & 117.90 & 1.0 \\
\hline
\end{tabular}


The activation energy values suggested the following sequence of thermal stability: diflunisal > tenoxicam > celecoxib. The differential scanning calorimetric (DSC) curves. Allowed determination of the melting points and the degree of purity of the drugs, starting from molecular masses of substances Purity determination is difficultly listed in USP in general chapter on thermal analysis [26]. The results obtained by the volumetric and spectrophotometric methods afforded values similar to those found by differential thermal analysis Table 2, comparison of the data on the anti-inflammatory drugs analyzed in this work reveals the importance of the (DSC) technique for the quality control of drugs. Also, the melting point obtained by DSC reveals the precision of the technique in yielding these thermal parameters.

Table 2: Degrees of purity and melting points of diflunisal, tenoxicam and celecoxib obtained by differential scanning calorimetric and pharmacopeial methods.

\begin{tabular}{|c|c|c|c|c|c|}
\hline \multirow{2}{*}{ Drug } & \multicolumn{2}{|c|}{ Degree of purity \% } & \multicolumn{3}{c|}{ Melting point, ${ }^{\circ} \mathrm{C}$} \\
\cline { 2 - 6 } & DSC & Pharmacopeial & DSC & DTA & Pharmacopeial \\
\hline Diflunisal & 98.89 & 98.97 & 211.62 & 218 & $211-213$ \\
\hline Tenoxicam & 98.63 & 98.95 & 218.51 & 220 & $209-213$ \\
\hline Celecoxib & 98.95 & 98.99 & 160.68 & 162 & $159-165$ \\
\hline
\end{tabular}

\section{Conclusion}

The thermal behavior of diflunisal, tenoxicam and celecoxib as anti-inflammatory drugs has been studied using TGA/DTA and differential scanning calorimetric (DSC) techniques.

a. The kinetic and thermodynamic parameters, activation energy (Ea), order of reaction (n), frequency factor $(\mathrm{Z})$ and activation entropy $(\Delta S \#)$ have been calculated.

b. The purity of three anti-inflammatory drugs, diflunisal, tenoxicam and celecoxib have been determined by differential scanning calorimetric (DSC), comparison of the data on the anti-inflammatory drugs analyzed in this work reveals the importance of the (DSC) technique for the quality control of drugs. Also, the melting points obtained by (DTA) and DSC reveal the precision and compatible of the two techniques in yielding these thermal parameters.

c. The thermal stability of anti-inflammatory drugs have been evaluated on the basis of the kinetic and thermodynamic parameters, suggest the following sequence of stability, diflunisal $>$ tenoxicam $>$ celecoxib.

The use of clean techniques, speed simplicity of the analytical methods applied to obtain the results are the reasons be hinging the even growing important of thermal analysis in the quality control of the active ingredients or medication.

\section{References}

1. Same RT, Nayak VG, Nalkar VB, Talanta (1985) An extractive spectrophotometric method for the determination of tetramisole hydrochloride in pharmaceutical preparations. Talanta 32(1): 148-149.

2. Guneri T, Sevgi F (1988) Acta Pharm Turc 30:129
3. Veenedaal JR, Meffin PJ (1984) Direct analysis of diflunisal ester and ether glucuronides by high-performance liquid chromatography. J Chromatogr 307(2): 432-438.

4. Riberia KA, de Oliveria JDS, Letes MIG, Jinz SA, Ionashiro M (1996) J Therm Anal 46: 1645-1655.

5. Glass BD, Cs Novak, ME Brown (2004) J Therm Anal Cal 77: 1013-1036.

6. Ford JL, Timmins P (1989) Pharmaceutical thermal analysis, Techniques and Applications, Willy, USA.

7. Vora A, Riga A, Dollimore D, Alkxander K (2004) Thermal stability of folic acid in the solid-state. J Therm Anal Cal 75: 709-717.

8. Silva MA, Kelmann RG, Foppa T, Cruz AP, Betrol CD, et al. (2007) Thermoanalyticalstudy of fluoxetine hydrochloride. I them Anal Cal 87: 463-467.

9. Cides LCS, Aruứjo AAS, Santos filho M, Matos JR (2007) Thermal behaviour, compatibility study and decomposition kinetics of glimepiride under isothermal and non-isothermal conditions. J Therm Anal Cal 84: 441-445.

10. Smidt E, Tinter J (2007) Application of differential scanning calorimetry (DSC) to evaluate the quality of compost organic matter. Thermochim Acta 459: 87-93.

11. Oberoi LM, Alexander KS, Riga AT (2004) Evaluation of an index based on van't Hoff equation to predict PEG-drug eutectic composition. J Therm Anal Cal 78: 83-89.

12. Giron D (1986) Applications of thermal analysis in the pharmaceutical industry. J Pharm Biomed Anal 4: 755-770.

13. Giron D, (1998) PSTT 1(191): 262

14. British Parmacopoeia (1993) British Pharmacopoeia Commission Secretariat, London.

15. LISP 23 (1995) The United States Pharmacopoeia, Ed 23, United States Pharmacopeial Convention, INC, Rockville.

16. Kissinger HE (1957) Reaction Kinetics in Differential Thermal Analysis. Anal Chem 29: 1702-1706.

17. Flynn JH, Wall LA (1966) General Treatment of the Thermogravimetry of Polymers. J Res Nat Bur Stand A Phys Chem, 70A: 487.

18. Flynn JH, Wall LA (1996) A quick, direct method for the determination of activation energy from thermogravimetric data. Polym Lett 4: 323-328.

19. Ozawa T (1965) A New Method of Analyzing Thermogravimetric Data. Bull Chem Soc Jpn 38: 1881-1886.

20. Coats AW, Redfern JP (1964) Kinetic Parameters from Thermogravimetric Data. Nature 201: 68-69.

21. Charles D Doyle (1965) Series Approximations to the Equation of Thermo gravimetric Data. Nature, 207: 290-291.

22. Madhusudanan PM, Krishnan K, Ninan KN (1993) New equations for kinetic analysis of non-isothermal reactions. Thermochim Acta 221: 1321.

23. Horowitz LL, Metzger G (1963) A New Analysis of Thermogravimetric Traces. Anal Chem 35: 1464-1468.

24. Flynn JH (1985) Degradation kinetics applied to lifetime predictions of polymers. Polym Eng Sci 20: 675-677.

25. Flynn JH (1988) Thermal analysis kinetics-problems, pitfalls and how to deal with them. J Therm Anal 34: 367-381.

26. USP 28 (2005) The united States Pharmacopoeia, Ed.28, United States Parmacopoeial Convention, INC, USA. 


\section{(C) (i) This work is licensed under Creative}

Submission Link: https://biomedres.us/submit-manuscript.php

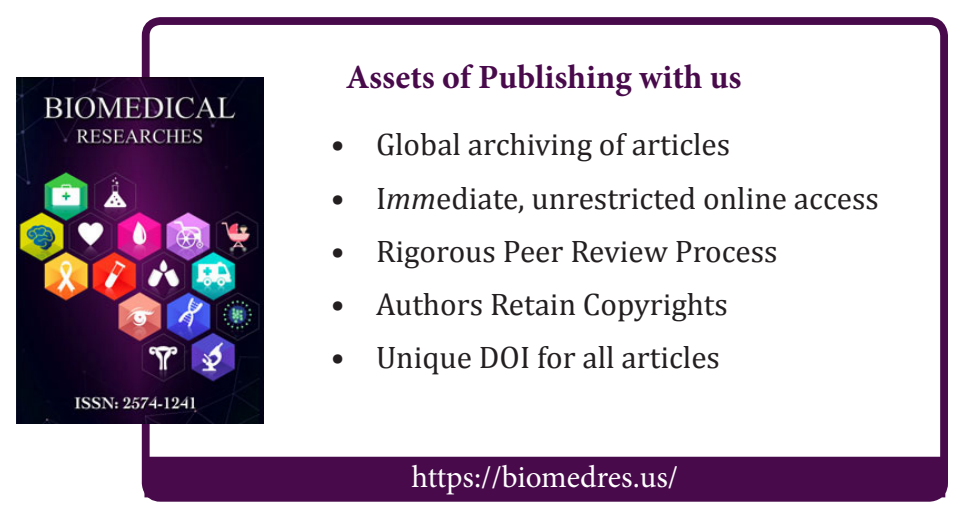

